\title{
Vaginal infections and its relation to preterm labour, PPROM, PROM and its outcome
}

\author{
Pradeep Shivaraju*, Pallavi Purra, Navatha Bheemagani, Krishna Lingegowda
}

Department of Obstetrics and Gynaecology, PESIMSR Medical College, Kuppam, Andhra Pradesh, India

\author{
Received: 05 August 2015 \\ Revised: 11 August 2015 \\ Accepted: 14 August 2015 \\ *Correspondence: \\ Dr. Pradeep Shivaraju, \\ E-mail: drpradi@gmail.com
}

Copyright: ( $)$ the author(s), publisher and licensee Medip Academy. This is an open-access article distributed under the terms of the Creative Commons Attribution Non-Commercial License, which permits unrestricted non-commercial use, distribution, and reproduction in any medium, provided the original work is properly cited.

\begin{abstract}
Background: Prematurity is the cause of $85 \%$ of neonatal morbidity and mortality. Recently, vaginal infection has been associated with increased risks for prematurity and premature rupture of membranes (PROM). Since preventive measures can prevent preterm labour and neonatal morbidity and mortality taking these facts into consideration the present study was undertaken to study the role of vaginal infection in preterm labour, PPROM, PROM.

Methods: A prospective observational study was done in PESIMR, Kuppam, Andhra Pradesh. The aim was to study the role of vaginal infections in preterm labour, preterm premature rupture of membranes (PPROM) and premature rupture of membranes (PROM). Objectives of the study were to diagnose vaginal infection by taking high vaginal swab, to study the relation of vaginal infection and preterm labour, PPROM, PROM, to evaluate maternal morbidity, mortality and neonatal outcome. The another objective was to select an appropriate antibiotic therapy. The study was done on 80 patients of preterm labour, PPROM and PROM. Vaginal infection was confirmed by high vaginal swab and neonatal outcome was noted.

Results: Out of 80, high vaginal swab had growth in 40 patients and 40 were sterile. CONS were the commonest isolated organism grown followed by candida. RDS was the commonest neonatal complication seen in mothers with vaginal infection who delivered prematurely, thus vaginal infection being a common cause of preterm labour, PPROM and PROM, timely detection and treatment is important to avoid prematurity, associated neonatal morbidity and mortality.

Conclusions: study provides important data about microbiological correlate of threatened preterm, preterm labour, PROM, PPROM in our pregnant women and most of pathological isolates were sensitive to ampicillin, taxim and gentamicin.
\end{abstract}

Keywords: Vaginal infection, Prematurity, Threatened preterm, Preterm labour, Premature rupture of membranes, Preterm premature rupture of membranes, Antibiotics

\section{INTRODUCTION}

Prematurity is the cause of $85 \%$ of neonatal morbidity and mortality. Preterm labour is any labour which starts before 37 completed weeks of gestation. Premature rupture of membranes (PROM) is spontaneous rupture of membranes after 37 weeks of gestation before the onset of regular uterine contractions. Preterm prelabour rupture of membranes (PPROM) is spontaneous rupture of membranes between 28-37 weeks of gestation without the onset of regular uterine contractions. Time interval from PROM to spontaneous labour suggests that $60 \%$ of women go into spontaneous labour within $24 \mathrm{hrs}$ of rupturing their membranes. The most serious outcome of preterm labour, preterm premature rupture of membranes is often associated with adverse maternal and neonatal outcomes related to infection. ${ }^{1}$ It has been estimated that $10 \%$ of perinatal deaths are directly or indirectly attributable to PROM. 
The causes of most preterm labour, PPROM, PROM is not known, but a variety of conditions have been shown to be associated with an increased risk of preterm delivery. One of the causes is infection and vaginal infection, a common vaginal syndrome in women of reproductive age, has been associated with increased risks for prematurity and premature rupture of membranes. ${ }^{2-6}$ Main cause for rupture of membranes is decrease or loss of tensile power of the membranes. The collagens are structural component for the tensile strength of the membranes.

The pathophysiology of infection causing PPROM is considered to be due to the production of prostaglandins and matrix-degrading enzymes via microbial endotoxins and pro-inflammatory cytokines (e.g. IL-8, IL1 $\beta$, TNF $\alpha$ ) which, in turn, are released after the binding of microorganisms to pattern-recognition receptors (e.g. toll-like receptors). ${ }^{7}$ These lead to increase in metalloproteinase, which is responsible for collagen degradation, hence there is decrease in the tensile power of membranes and leads to its rupture.

Prostaglandins play a major role in stimulating uterine contractions, while degradation of the extracellular matrix in foetal membranes is implicated in PPROM. ${ }^{7,8}$ However, infection caused by ascending microorganisms may also occur secondary to PPROM. ${ }^{9,10}$ Hypothesis is that several organisms that are commonly present in the vaginal flora, including group Ecoli, B streptococci, Staphylococcus aureus and microorganisms that cause Bacterial Vaginosis, secrete proteases that degrade collagen and weaken the foetal membranes leading to PROM. $^{11,12}$

Intrauterine infection has been demonstrated in up to $60 \%$ of cases. ${ }^{9,10}$ More recent data suggest that some microbes invade the amniotic cavity from the bloodstream after dissemination from remote sites, e.g. from the gastrointestinal tract. ${ }^{13}$ The single greatest threat to infant with preterm labour, PPROM and PROM is respiratory distress syndrome (RDS). Prematurity is associated with nearly $70 \%$ of perinatal mortality in India. ${ }^{14}$ There is increased incidence of perinatal mortality which may be due to RDS, infection, asphyxia and congenital anomalies. Other causes of death are cord accidents, intracranial haemorrhage, trauma, necrotizing enterocolitis. Inefficient blood brain barrier makes them more prone for brain damage.

Since preventive measures can prevent the above phenomena, taking these facts into consideration the present study was undertaken to study the role of vaginal infection in preterm labour, PPROM, PROM and maternal and foetal outcomes.

\section{METHODS}

This prospective observational study was conducted from January 2011 to December 2011 in PESIMSR, kuppam for a period of 1 year. Written informed consent was obtained from enrolled women. Patients with live fetus and gestational age above 28weeks till term were included in the study. Women who presented to the labor and delivery unit with complaints suggesting rupture of chorioamniotic membranes and with threatened preterm and preterm labour were enrolled as cases. Patients with maternal complications like multiple pregnancies, antepartum hemorrhage, polyhydramnios, preeclampsia, eclampsia, diabetes mellitus and congenital malformed fetus, already received antibiotics for PPROM were excluded from study.

History, general physical and obstetrical examinations were done. Enrolled women were evaluated using a sterile speculum examination. The diagnosis of spontaneous rupture of the membranes was confirmed by inspection of the cervix, for flow of amniotic fluid from the cervical so by asking the patient to cough. The amount, colour and smell of the fluid were assessed. Based on the findings of cervical diltation and uterine contractions patients were categorized as preterm labour (uterine contractions $4 / 20^{\prime \prime} / 10^{\prime}$, cervical dilatation $\geq 3 \mathrm{~cm}$, effacement $\geq 80 \%$ ) or threatened preterm labour (uterine contractions $<20$ seconds, cervical dilatation. Swab from the posterior fornix of the vagina was taken and sent for Gram's staining and culture sensitivity. Total count, differential count and urine analysis was done for all cases. All the patients were monitored for fever, maternal tachycardia, uterine tenderness, and foul smelling vaginal discharge. The neonatal out come in patients who delivered was noted.

Microbiological analysis- Vaginal swabs were obtained from cases and controls and sent to the Department of Microbiology. The Gram's staining was done followed by inoculation on Blood and MacConkey agar as per standard protocols. After overnight incubation, plates were checked for growth. Identification of pathogen was done and the significant pathogen was then evaluated for antimicrobial susceptibility testing using commonly used antibiotics for aerobic (Ampicillin, Cefazolin and Gentamicin). Cultures for anaerobic bacteria were not done as metronidazole is an effective drug for all type of anaerobes.

\section{RESULTS}

Out of the 80 cases of high vaginal swab culture study, 40 cases were positive $\& 40$ cases were sterile (Table 1 ).

Table 1: Baseline characteristics of study population.

\begin{tabular}{|ll|}
\hline High vaginal swab growth & Number \\
\hline Positive & $40(50 \%)$ \\
\hline Negative & $40(50 \%)$ \\
\hline Total & 80 \\
\hline
\end{tabular}


Out of 80 patients studied 31 were of preterm labour, 15 of threatened preterm labour, 24 of PROM, 10 of PPROM (Table 2).

Table 2: Total number of cases.

\begin{tabular}{|ll|}
\hline Cases presented as & Number \\
\hline Threatened preterm & $15(18.75 \%)$ \\
\hline Preterm labour & $31(38.75 \%)$ \\
\hline PROM & $24(30 \%)$ \\
\hline PPROM & $10(12.50 \%)$ \\
\hline Total & $80(100 \%)$ \\
\hline
\end{tabular}

Out of 15 cases of threatened preterm 12(80\%) patients were conserved due to prompt treatment of infections (Table 3).

Table 3: Threatened preterm cases.

\begin{tabular}{|ll|}
\hline Threatened preterm & Number \\
\hline Conservatively managed & $12(80 \%)$ \\
\hline Delivered & $3(20 \%)$ \\
\hline Total & 15 \\
\hline
\end{tabular}

Out of 15 cases, 8cases of positive culture in threatened preterm labour, $12(80 \%)$ cases were conserved and $3(20 \%)$ had pre- term delivery. This suggests that if the infections are promptly treated preterm delivery can be avoided. Most of the patients studied were between 32 37 weeks 44 cases $(55 \%)$ (Table 4$)$.

Table 4: Gestational age of the patients studied.

\begin{tabular}{|ll|}
\hline Gestational age & Number \\
\hline $28-32$ weeks & $12(15 \%)$ \\
\hline $32-37$ weeks & $44(55 \%)$ \\
\hline $37-40$ weeks & $20(25 \%)$ \\
\hline$>40$ weeks & $4(5 \%)$ \\
\hline \hline Total & $80(100 \%)$ \\
\hline
\end{tabular}

Table 5: High vaginal swab culture positive in patient studied.

\begin{tabular}{|ll|}
\hline Cases presented & Culture positive \\
\hline Threatened preterm(15) & $8(53.33 \%)$ \\
\hline Preterm labour $(31)$ & $18(58.06 \%)$ \\
\hline PROM(24) & $7(29.16 \%)$ \\
\hline PPROM $(10)$ & $7(70 \%)$ \\
\hline Total 80 & 40 \\
\hline
\end{tabular}

Out of 80 cases, 68 cases delivered out of which 53 were vaginal delivers $(77.94 \%)$; caesarean sections were 15 $(22.05 \%)$ (Table 7).
Table 6: Duration of leak (hours) of patients studied (PROM, PPROM).

\begin{tabular}{|ll|}
\hline $\begin{array}{l}\text { Duration of leak(hours) to } \\
\text { delivery interval }\end{array}$ & Number \\
\hline $1-5$ & $8(23.5 \%)$ \\
\hline $6-10$ & $16(47 \%)$ \\
\hline $11-20$ & $10(29.4 \%)$ \\
\hline$>20$ & $0(0 \%)$ \\
\hline \hline Total & $34(100 \%)$ \\
\hline
\end{tabular}

Table 7: Mode of delivery in patients studied.

\begin{tabular}{|ll|}
\hline Mode of delivery & Number \\
\hline Vaginal deliveries & $53(77.94 \%)$ \\
\hline Caesarean section & $15(22.05 \%)$ \\
\hline Total & 68 \\
\hline
\end{tabular}

Table 8: Birth weight (kg) of newborn.

\begin{tabular}{|lc|}
\hline Birth weight & Number \\
\hline$<2 \mathrm{~kg}$ & $2(2.94 \%)$ \\
\hline $2-2.5 \mathrm{~kg}$ & $17(20.3 \%)$ \\
\hline $2.5-3.5 \mathrm{~kg}$ & $48(79.7 \%)$ \\
\hline$>3.5 \mathrm{~kg}$ & $1(1.47 \%)$ \\
\hline \hline Total & $68(100 \%)$ \\
\hline
\end{tabular}

Table 9: Complications of neonate.

\begin{tabular}{|cll|} 
Complications & $\begin{array}{l}\text { Delivered } \\
(\mathrm{n}=68)\end{array}$ \\
\hline Complications Present & $14(20.5 \%)$ \\
\hline$\bullet$ & Birth asphyxia & $2(2.94 \%)$ \\
\hline$\bullet$ & RDS & $5(7.35 \%)$ \\
\hline$\bullet$ & Very low birth & $3(4.41 \%)$ \\
\hline$\bullet$ & Neight & $2(2.94 \%)$ \\
\hline$\bullet$ & MAS & $1(1.47 \%)$ \\
\hline \hline$\bullet$ & Death & $1(1.47 \%)$ \\
\hline
\end{tabular}

CONS (coagulase negative staphylococcus auerus) formed the largest group of positive culture study 15 $(23.4 \%)$. The next organism isolated was Candida albicans $7(7.8 \%)$. Ecoli. was isolated in $2(3.1 \%)$ of the cases Table 11.

Ampicillin, Cefotaxim, Gentamicin is effective in most of the organism especially in CONS, E. coli (Table 11). Out of total 68 births 14 neonates had complications Table 9. Of the different complication seen in the neonates RDS $7.35 \%$ and it was most seen in preterm births and PPROM. Neonatal death was seen in 1 neonate out of 68 births. Neonatal death was due to extreme prematurity. In cases of neonatal sepsis, all mothers had growth in high vaginal swab $(100 \%)$. 
Table 10: High vaginal swabs growth in patients studied.

\begin{tabular}{|c|c|}
\hline Vaginal swab growth & Number \\
\hline No growth & $40(50 \%)$ \\
\hline Growth & $40(50 \%)$ \\
\hline - Candida & $7(7.8 \%)$ \\
\hline - $\quad$ CONS & $15(23.4 \%)$ \\
\hline - $\quad$ E.coli & $2(3.1 \%)$ \\
\hline - $\quad$ Enterococci & $2(3.1 \%)$ \\
\hline - $\quad$ Klebsiella & $2(3.1 \%)$ \\
\hline - $\quad$ MRSA & $1(1.6 \%)$ \\
\hline - $\quad$ Proteus mirabilis & $1(1.6 \%)$ \\
\hline $\begin{array}{ll}\text { - } & \text { Pseudomonas } \\
\text { aeurogenosa }\end{array}$ & $2(3.1 \%)$ \\
\hline - $\quad$ Staphylococcus aureus & $1(1.6 \%)$ \\
\hline - $\quad$ Streptococcus & $1(1.6 \%)$ \\
\hline
\end{tabular}

Table 11: Antibiotics sensitivity in high vaginal swab culture positive patients.

\begin{tabular}{|ll|}
\hline Antibiotics & Sensitivity \\
\hline Ampicillin & $27(67.5 \%)$ \\
\hline Taxim & $7(17.5 \%)$ \\
\hline Gentamycin & $6(15 \%)$ \\
\hline \hline Total & $40(100 \%)$ \\
\hline
\end{tabular}

\section{DISCUSSION}

In this prospective observational study, we performed lower genital tract culture in pregnant women with PPROM, PROM, and threatened preterm and preterm labour and studied the vaginal infection and their antibiotic sensitivity and maternal and neonatal outcome. Most common isolated bacteria were CONS followed by candida. In resource limited settings where microbiological evaluation of amniotic fluid is not feasible, identification of bacteria in high vaginal swab can guide antibiotic therapy in women with PPROM. Previous studies have shown good correlation between genital tract flora and organism grown in amniotic fluid or blood of neonates with early onset sepsis.

In studies by Naeye et $\mathrm{al}^{15}$, McDonald et al, ${ }^{16}$ Das et $\mathrm{al}^{17}$ showed that infection was 2 -3 times more common in patients with rupture of membranes before 37 weeks of gestation than when foetal membranes ruptured at term. In our study 7 (70\%) cases out of 24 cases of PPROM, 7 (29.16\%) cases out of 24 cases PROM, 8 cases $(53.33 \%)$ out of 15 threatened preterm, and 18 cases out of 31 cases were culture positive.

E-coli was the commonest organism isolated in the study done by Sharma, ${ }^{18}$ Das et al $^{17}(44 \%)$, Raunt et al, ${ }^{19}$ Agarwal et al. ${ }^{20}$ In our study too the commonest bacteria isolated was CONS15 (23.4\%). The next common organism isolated was Candida albicans 7 (7.8\%).
In a study done by Lanier $\mathrm{Jr}$ et al, the incidence of chorioamnionitis after PROM is $20 \% .^{21}$ In the present study there was no case of clinical chorioamnionitis. This probably was because all the patients in the study were given prophylactic antibiotics and were delivered before $24 \mathrm{hrs}$ from the onset of PROM, PPROM.

A study done Swati Pandey, where neonatal sepsis was seen in $25 \%$ of the cases. ${ }^{22}$ Our study showed $2.94 \%$ cases ( 2 out of 68 delivered) of neonatal sepsis and the mothers of these two neonates had growth in vaginal swabs suggesting vaginal infection. The incidence of neonatal sepsis was less as the neonate after birth received injectable antibiotics.

Antibiotic therapy in PPROM has been associated with significant reduction in incidence of chorioamnionitis, birth within one week of starting antibiotics and improved neonatal outcomes. Due to difficulty in obtaining amniotic fluid samples and various reports indicating mixed bacterial growth in amniotic fluid cultures, broad spectrum antibiotics are prescribed during expectant management of PPROM. ${ }^{23}$ ACOG also recommends a 7 day course oral or parenteral of Ampicillin or Amoxicillin and Erythromycin in pregnant women with PPROM who are remote from term. ${ }^{24}$ This approach although simplistic can lead to inadequate treatment if causative organisms are resistant or not sensitive to these antibiotics. Also wide spectrum resistance to penicillin group of antibiotics has been reported previously from India and other developing countries. $^{24,25}$

\section{CONCLUSIONS}

Prematurity is an important problem in obstetrics. Vaginal infection being a common cause of preterm labour, PROM and PPROM, timely detection and treatment is important to avoid prematurity, associated neonatal morbidity and mortality. Our study provides important data about microbiological correlate of threatened preterm, preterm labour, PROM, PPROM in our pregnant women and most of pathological isolates were sensitive to ampicillin, taxim and gentamicin.

Funding: No funding sources

Conflict of interest: None declared

Ethical approval: Not required

\section{REFERENCES}

1. Gynecol Obstet Invest. 2006; 61(3):135-8. E pub 2005 Dec 5.

2. Eschenbach, D. A., M. G. Gravett, K. C. S. Chen, U. B. Hoyme et al 1984. Bacterial vaginosis during pregnancy. An association with prematurity and postpartum complications, p. 213-222. Statistics with confidence. Br. Med. J.

3. Gravett MG, Hummel D, Eschenbach DA, Holmes KK. Preterm labor associated with subclinical 
amniotic Fluid infection and with bacterial vaginosis. Obstet. Gynecol. 1986;67:229-37.

4. Gravett MG, Nelson HP, DeRouen T, Critchlow CC, et al. Independent association of bacterial vaginosis and Chlamydia trachomatis infection with adverse pregnancy outcome. Jama. 1986;256:1899-903.

5. Martius J, Krohn MA, Hillier SL, Stamm WE, et al. Relationships of vaginal Lactobacillus species, cervical Chlamydia trachomatis, and bacterial vaginosis to preterm birth. Obstet Gynecol. 1988;71:89-95.

6. McGregor JA, French JI, Richter R, et al. Antenatal microbiologic and maternal risk factors associated with prematurity. Am J Obstet Gynecol. 1990;163:1465-73.

7. Goldenberg RL, Culhane JF, Iams JD. et al. Epidemiology and causes of preterm birth. Lancet.2008;371:75-84.

8. Romero R, Baumann P, Gomez R. et al. The relationship between spontaneous rupture of membranes, labor, and microbial invasion of the amniotic cavity and amniotic fluid concentrations of prostaglandins and thromboxane B2 in term pregnancy. Am J Obstet Gynecol. 1993;168:16541664.

9. Mercer B M, Goldenberg R L, Das A F. et al. What we have learned regarding antibiotic therapy for the reduction of infant morbidity after preterm premature rupture of the membranes. Semin Perinatol.2003;27:217-230.

10. Mercer B M. Preterm premature rupture of the membranes. Obstet Gynecol. 2003;1101:178-193.

11. McGregor JA, French JI, Lawellin D et al Bacterial protease-induced reduction of chorioamniotic membrane strength and elasticity. Obstet Gynecol 1987; 69:167-74.

12. Draper D, Jones W, Heine RP et al. Trichomonas vaginalis weakens human amniochorion in an in vitro model of premature membrane rupture. Infectious Disease Obstet Gynecol. 1995;2:267-74.

13. DiGiulio DB, Romero R, Kusanovic JP. et al. Prevalence and diversity of microbes in the amniotic fluid, the fetal inflammatory response, and pregnancy outcome in women with preterm pre-labor rupture of membranes. Am J Reprod Immunol. 2010;64:38-57.

14. Mehta A. prematurity $-\mathrm{A}$ Review. J of obst gyn India. 1971;21:453-61.

15. Naeye RL, Dellinger WS, Blac WA. Fetal and maternal features of antenatal bacterial infection. Am J. Pediatrics 1978; 61:171.

16. McDonald HM, O’ Loughlin JA, Jolly P, et al. Br J Obstet Gynecol. 1991;98(5):427-35.

17. Das C. R, Pattnaik PL, Sahoo PK. Prevalence of vaginal infection in preterm labour. Antiseptic 1996 April;93(4):140-43.

18. Sharma JB, Prevalence of pathogenic Bacteria in Genital tract in preterm labour. J Obstet Gynecol India. 1989;229.

19. Raunt M. D, Dora H, Premature rupture of membrane - A clinical and bacteriological study. J of Obst Gyn 1988;38(1-6);184-7.

20. Agarwal SK, Rathi AK, Asha Awasthi, et al. J of Obst Gyn of India 1979:40-44.

21. Lanier RL Jr, Carbraugh RW et al Incidence of maternal and foetal complications associated with rupture of membranes before onset of labour. Am J Obstet Gynecol. 1965;93:398.

22. Swati Pandey, Anupama Dave, Bandi S. Maternal and foetal outcome in cases of PROM J. Obstet Gynecol Ind. 2000;50(1):63-5.

23. Dudley J, Malcolm G and Ellwood D. Amniocentesis in the management of preterm labour $\mathbf{J}$ of Obst Gyn 1988;38(1-6);184-7.

24. Mathew R, Kalyani J, Bibi R, Mallika M. Prevalence of bacterial vaginosis in antenatal women. Indian $\mathbf{J}$ Pathol Microbiol. 2001;44(2):113-6.

25. ACOG Practice Bulletin No. 80: premature rupture of membranes. Clinical management guidelines for obstetrician gynecologists. Obstet Gynecol. 2007;109(4):1007-19.

Cite this article as: Shivaraju $\mathrm{P}$, Purra $\mathrm{P}$, Bheemagani N, Lingegowda K. Vaginal infections and its relation to preterm labour, PPROM, PROM and its outcome. Int J Reprod Contracept Obstet Gynecol 2015;4:1422-6. 